DOI: https://doi.org/10.47405/mjssh.v6i5.777

\begin{tabular}{|c|c|}
\hline 4.581 & Malaysian Journal of Social Sciences and Humanities (MJSSH) \\
\hline $\begin{array}{l}\text { Malaysian Journa of } \\
\text { socal selenes and }\end{array}$ & Volume 6, Issue 5, May 2021 \\
\hline (MJ-SSH) & e-ISSN : 2504-8562 \\
\hline & $\begin{array}{l}\text { Journal home page: } \\
\text { www.msocialsciences.com }\end{array}$ \\
\hline
\end{tabular}

\title{
Revisiting PULSE 2 Textbook after Three Years: Have Teachers Changed Their Mind?
}

\author{
Mohamad Syafiq Ya Shak ${ }^{1}$, Norasyikin Abdul Malik ${ }^{2}$, Nurul Ain Hasni², Mohd Haniff Mohd Tahir' \\ ${ }^{1}$ Faculty of Language and Communication, Universiti Pendidikan Sultan Idris, 35900 Tanjung Malim, Perak, Malaysia \\ ${ }^{2}$ Academy of Language Studies, Universiti Teknologi MARA Perak Branch Seri Iskandar Campus, 32610 Seri Iskandar, \\ Perak, Malaysia
}

Correspondence: Mohamad Syafiq Ya Shak (moham381@uitm.edu.my)

\begin{abstract}
The present study aims to further explore Malaysian secondary English teachers' perspective on the use of PULSE 2 in their language classrooms, after three years of its introduction in Malaysian secondary schools. The study is qualitative in nature, employing semi-structured interview as the approach for data collection the data. However, due to the Movement Control Order (MCO) the study was conducted through a Mobile Instant Messaging (MIM) application, WhatsApp. ATLAS ti. was employed to perform the content analysis to the collected data. The findings revealed that the respondents preferred to use imported English textbooks with local modifications in their language classroom. Most of them also felt that the level of the language content and skills offered by PULSE2 did not match with their students' abilities. They also reported grouses about the difficult foreign content of PULSE 2, which indicated that they have yet to change their mind about it even after using it for three years. It is suggested that relevant stakeholders such as the Ministry of Education Malaysia (MOE) to review the use of imported textbooks such as PULSE 2 in Malaysia, as this will bear an impact on the creation of the country's version of the Common European Framework of Reference for Languages (CEFR) called 'CEFR-M' as projected in the on-going English Language Education Reform in Malaysia by 2025. Not only that, selecting a textbook that is relatable, localized, and matches the students' level is crucial in this COVID-19 era, where the new normal in education forces learning to be done remotely. Inevitably, there will be students who are less privileged, and their only hope to gain access to continuous education is through a textbook that can easily be used for self-study and is readily available, without having the needs to have access to advanced technological devices.
\end{abstract}

Keywords: CEFR, ESL, PULSE 2, COVID-19, imported textbook

\section{Introduction}

As the Ministry of Education Malaysia (MOE) decided that the Common European Framework of References for Language or CEFR is the new direction that will be adopted in English Language teaching and learning in Malaysia, it is inevitable that the syllabus, assessments, and materials will need to be re-evaluated to ensure that they are CEFR-aligned. One major move in this exercise is the introduction of CEFR-aligned textbooks to replace the previous textbooks for both primary and secondary school students. In the case of Malaysian secondary school students, locally produced textbooks for Form 1 and Form 2 students, 'English Form 1' and 'English Form 2' were replaced by a single, imported textbook called 'PULSE 2'. On paper, PULSE 2 ticks all the boxes for a working textbook. There are a variety of themes in the book. It covers all the four important skills in English 
(reading, writing, listening, and speaking) it is written by a native speaker, it is colorful, it brings English language in an integrated manner, and it offers digital tie up and a Teacher's Book. However, the reactions to the implementation of it in Malaysian schools have been varied. There are contentious arguments made by both its advocates and critics on whether this textbook is the answer to the roll out of the CEFR in Malaysia. This has definitely raised concerns among Malaysians as "textbooks are one of the elements that may promote or discourage learners depending on their materials" (Zohrabi, Sabouri, \& Kheardman, 2014, p. 95).

Earlier, Johar and Abdul Aziz (2019) examined the teachers' perceptions in using the PULSE 2 textbook in Malaysian secondary schools by interviewing five teachers from a secondary school in Marang, a district in the state of Terengganu, Malaysia. Mixed perceptions were disclosed by the respondents. Among others, the teachers were generally positive about their students' engagement with 'PULSE 2'. They felt that even though the content of PULSE could prove to be challenging for low level students, it is still engaging and useful to be used in their lessons due to its variety of activities. Because of this, they were able to explore various methodologies in English Language teaching. In addition, the teachers also believed that 'PULSE 2' has allowed rooms for personalization and encouraged their students to think critically and not merely rote learning, which "simultaneously provided space for critical thinking and reflective learning, making learners as reflective practitioners, which then engenders authentic language learning" (2019, p.10). Nevertheless, they wished that some of the vocabularies could be changed as they were deemed as too difficult for the students and this might hinder them from achieving the 'A2' CEFR level as indicated by the MOE.

With regards to PULSE 2's cultural content however, majority of the interviewees in the study by Johar \& Abdul Aziz (2019) agreed that it was of limited relevance to their students. They argued that 'PULSE 2' did not reflect any Malaysian identity as it was intended for a different set of audience. Yet, all respondents did agree that 'PULSE 2' is indeed appropriate to be used in introducing different culture contexts to the students. It is later suggested that due to its limited cultural content of Malaysia, 'PULSE 2' is not relevant for Malaysian students. They indicated that with minimal direct connection to the students' schemata, learning could not take place efficiently as 'the students' schemata and previous knowledge should be connected well" (2019, p.13).

However, the researchers believe that Johar and Abdul Aziz's (2019) assertion about PULSE 2 can be further examined. This is because the result of the study might be skewed due to its small number of participants and locality. It was only done in one school; there might be other issues that are unique to that school that could affect the teachers' perception. In addition, it was conducted in a rural school; conducting the study in different settings could provide additional perspectives on the teachers' perception in using PULSE 2.

Hence, this study aims at further exploring Malaysian secondary English teachers' perception on the use of PULSE 2 in their language classrooms, after three years of its introduction in Malaysian secondary schools. It was still conducted in the state of Terengganu, however, it has been expanded to three different districts which are Hulu Terengganu, Kuala Terengganu, and Kemaman which represent teachers from three diverse settings which are rural, urban and semi-urban schools respectively. The study intends to answer these three questions:

1. Which type of English textbook that teachers prefer to be used with their students?

2. How have language skills and content been dealt with in PULSE 2?

3. What are the issues that the teachers have experienced in using PULSE 2?

\section{Literature Review}

\section{Reactions to the introduction of PULSE 2}

The introduction PULSE 2 has been embraced by some segments of the educational field. The MOE has resorted into using off-the-shelf books for Malaysian students because locally produced textbooks are yet to meet the new CEFR levels (Chin \& Rajaendram, 2017). Aziz (2017) seemed to agree with 
this notion as she reiterated the stand of the English Language Standards and Quality Council of Malaysia (ELSOQ) which stressed on the importance of getting quality CEFR-aligned textbooks while experts are identified and expertise is developed to produce future local textbooks that are fit for Malaysian students, while "ensuring students achieve proficiency levels aligned to international standards" (Chin \& Rajaendram, 2017, p.2). In addition, The National Union of the Teaching Profession Malaysia (NUTP) felt that it was only natural to use imported textbooks because the content is more current and cost-efficient (Chin \& Rajaendram, 2017). Likewise, the Parent Action Group for Education (PAGE) believed that such a move could boost students' English proficiency, while showering praise to a higher level of English among the students of private and international schools who are already using imported textbooks as opposed to the local students (Ariz, 2017a). This is because it is assumed that "the standards of the current local textbooks were too low, which prevented students from reaching a higher level of learning" (2017a, p.2). Several academicians also thought that this initiative would expose local students to a higher level of English, while promoting acceptance of other cultures and broadening one's viewpoint in aspects like culture, religion, and lifestyle (Ariz, 2017a). This could be attributed to the greater variety of culture content offered by these imported textbooks which tend to encourage the students to think and immerse in the said content as a 'citizen of the world'.

However, the backlash towards the roll out of PULSE 2 was also swift, especially in terms of its content. Among others, the relevance of PULSE 2's content was questioned, as the book is intended for Spanish students, with many Spanish words and phrases being peppered throughout the book (Ariz, 2017a; 'DAP slams ministry over English textbooks made for Spain', 2017). It is argued that with a very low level of English proficiency among Malaysian students, this textbook will only provide additional mental burden to them as they must digest the global content and acquire the language at the same time (Ariz, 2017b; Hammim, 2018). In addition, it was warned that using materials that are 100\% different from the local context could be simply too much, as it will make students especially those who reside in rural areas feel like they are in an alien environment (Chow, 2017).

Later, 'Let's have our own textbooks' (2018) also stressed that it is crucial for textbooks to have relatable content that connects more to the local context because "because contextual learning, which connects the content being taught, to the pupil's daily lives, the community around them, and the world, facilitates more effective learning $(2018$, p.2). Moreover, it was also claimed that foreign content could widen the learning gap between urban kids, with accessibility to explore various resources related to the foreign content in enhancing their understanding about the content, and rural kids, who are mostly dependent on textbooks and their own teachers for knowledge and to get clarity about the world.

There was also the question of the synchronization of this textbook to the curriculum. Abdul Aziz, Ab Rashid, and Wan Zainudin (2018) for instance argued that as it is already available in the market before the introduction of the CEFR in Malaysia, they do not work in unison with the new curriculum standard and the proposed scheme of work provided by the MOE. They specified that there is little synchronization between the textbook, the curriculum, and the scheme of work, and this "led to teachers not following in their lesson planning and instead, based their teaching on the curriculum and textbook only" (2018, p.414).

On the other hand, doubts were also raised about the preparedness of the English teachers who will use PULSE 2 (Ariz, 2017a; Ariz, 2017b; Chow, 2017). It was reported teachers were not properly trained to handle the book, since only one teacher per school was sent for training and this teacher will be required to train other English teachers at his or her establishment ('Teachers are not trained properly to use English textbooks, says parents' group', 2017). The MOE was later urged to be efficient in allowing the teachers to be "upskilled" for the purpose [of using PULSE 2]" (Ariz, 2017a, p.2) and to "be accountable for ensuring teachers are capable of guiding students to use the new textbooks" (Ariz, 2017c, p.1).

\section{Disputed culture content in PULSE 2}


As previously mentioned, PULSE 2 is produced for Spanish students with a notably different culture and way of life. Hence the culture content in the book is deemed as of limited relevance to Malaysian students. Some parties fear that the nation is doing a great disservice to children who use 'PULSE 2', as "Malaysia has its own brand of English that is used by speakers with 'their own cultural values, pragmatic norms, and world views' (Marlina, 2017, p. 2). There are several instances from the textbook itself that might raise eyebrows about its applicability.

Firstly, it is claimed that students must have basic Spanish knowledge to answer some of the questions in the book ('DAP slams ministry over English textbooks made for Spain', 2017). For example, on page 8 of PULSE 2, Exercise 5 asks the students what the Spanish word for 'poster' is. The answer is 'cartel'. A second question later asks students: 'How do you say 'lápiz' in English?' The answer is 'pencil'. With no prior knowledge of Spanish as the language is not offered in school, it will certainly be a challenge for Malaysian students to complete this exercise.

Secondly, the book also contains specific examples of exercises that require students to have an understanding of the foreign references (Zairil, 2017c). For instance, the students will need to first understand the significance of an Amish teenager's (from Mississippi, America) visit to London on page 75 or what is the merit for them to volunteer themselves especially at Dartmoor National Park (page 48) before they can proceed with rest of the activities in that Unit.

Thirdly, it is also assumed that the topics offered by 'PULSE 2' might be distant and alien to the local students (Aziz, 2017). For example, the first unit of 'PULSE 2' deals with a topic on celebrations. Celebrations such as Easter and Valentine's Day might not be very familiar to some Malaysian students. In the following pages, words like "jumper" and "trainers" are used to describe the clothes one wears. Again, these might not be the clothes that Malaysian students will wear to school and perhaps, they have other ways of saying or representing these clothes.

However, Hajar and Ali (2019) pointed out PULSE 2 also provides content that allows the students to reflect on their own culture as they embark on a particular topic and unit through the 'Cultural Comparison' part that each unit of the book offers. For example, a topic in Unit 8 'Good Luck, Bad Luck' that deals with Irish beliefs and Superstitions on page 88 also encourages students to compare the superstitions and beliefs that exist in students' own culture with the ones they are currently learning.

\section{Studies Related to PULSE 2}

Studies related to PULSE 2 are still in their initial stage, as the textbook was only introduced in 2017. Apart from Johar and Abdul Aziz (2019), at least two more studies have attempted to analyse multiple aspects of PULSE 2. Hajar and Ali (2019) scrutinized the cultural content of both local and imported textbooks used in English language teaching in Malaysia. They calculated the percentage of 'Source Culture' content (content related to Malaysian culture), 'Target Culture' (content related to the Native Speakers' culture such as the people in the US, UK, Canada, Ireland, and Australia), and 'Other Cultures' (content related to cultures other than 'Source' and 'Target' cultures). The results seemed to confirm the assertion that imported textbooks are of limited relevance, at least to the local culture of its users. Out of 89 items in the book which were identified as related to culture, 'PULSE 2' offers 55\% of the 'Target Culture' content (49 items), $45 \%$ of the other cultures content (40 items), and an unfortunate $0 \%$ of the 'Source Culture' content. This is a stark contrast to the local textbook, where the local content is front and center. Out of 91 items which were classified as culture-based, the book provides a huge $67 \%$ of the 'Source Culture' content (61 items), $21 \%$ of the other cultures content (19 items), and only $12 \%$ of the 'Target Content' (11 items).

On the other hand, with regards to PULSE 2's language skills content, Goh and Abdul Aziz (2020) disclosed that many teachers displayed positive perceptions towards using the speaking activities in 'PULSE 2' in teaching speaking skills to their students due to the features of the activities, where "the general aspects of the speaking activities, speaking skills, pronunciation and extended tasks do provide sufficient input to help teachers in delivering their lessons" (2020, p.63). Not only that, the respondents 
also found the book to be useful and practical for assessment purposes because it made it easier for them to assess their pupils.

\section{Importance of relevant cultural and social representation in an English language textbook}

Cultural and social representation in a textbook, especially in ESL and EFL settings could become one of the more important considerations in choosing a textbook. Although Cunningsworth (1984) argued that time "would be better spent learning the language rather than the structuring of the social world in which the learner is never likely to find himself" (1984, p.61), Pulverness and Tomlinson (2013) implied that language and culture are inextricably intertwined, in which treating language as a "valuefree code is likely to deprive learners of key dimensions of meaning and to fail to equip them with necessary resources to recognize and respond appropriately to the cultural subtext of language in use" (2013, p.446). Bader (2017) seemed to agree with this assessment, as he warned that "cultural representation in textbooks needs to be considered with precaution so as to prevent the denial of one's culture and thus one's identity, or the total rejection of the target culture which leads to an alienation in a shrinking world" (2017, p.102). It is thought that when a textbook is overwhelmed with contents of the target culture (English culture) and is deemed as too foreign with little or no representation of its users' own culture in it, the learners will have difficulties in terms of "integrating the unfamiliar cultural aspects and the linguistic forms of the target language concurrently" (Aytug, 2007, p.28). This matter has been proven by Thirunavakarasu \& Raja Harun (2021), where they indicated that the use of familiar cultural content for example "has a significant effect on reading comprehension, recall, and retelling (2021, p. 20), in which the use of reading texts which are incompatible with the learners' culture can impede the process of remembering and comprehending the said texts. Moreover, Nguyen (2015) worried that the situation will become more difficult for children who still do not have enough background knowledge to understand a particular global issue and they may develop feelings of unease and show signs of being uncomfortable in learning a language, which could lead to a total rejection to the language.

Not only that, this matter might result in some resistance towards the use of a particular textbook. A case in point will be the pushback on the use PULSE 2 as the textbook portrays zero local content, as discussed earlier. This situation also seems to be in contrast with the Malaysian Education Blueprint (2015-2025), which puts a big emphasis on the language users' understanding of the cultural context of communication. Al-Shammari (2015) also reported a similar contentious situation in Saudi Arabia as English textbooks which are primarily based on the USA textbook have failed to provide "any consideration to the Arabic or Islamic culture, and contrast sharply with the traditions and values of the Saudi lifestyle" (Al-Shammari, 2015, p.367).

Most importantly, having relevant content is crucial for successful second language acquisition. This is heavily emphasised in Krashen's (1982) Second Language Acquisition Theory. The Input hypothesis offered by this theory insists that language acquisition occurs when learners are presented with a "comprehensible input' where they receive input that they can understand, in which "understand" here means that "the [learners are] focused on the meaning and not the form of the message" (p.21). Therefore, it is essential that learners are presented with as much comprehensible input as possible in their language classroom, which could come in the form of relevant cultural portrayal that they could understand and deduce meaning from, through an English language textbook.

\section{Methodology}

\section{Design and Research Procedure}

The current study is qualitative in nature. A semi-structured interview was chosen as the main approach to collect the data. This study primarily pursues to discover (i) the type of English textbook that teachers prefer to be used with their students, (ii) the ways language skills and content have been dealt 
with in PULSE 2 according to teachers, and (iii) the issues that the teachers have experienced in using PULSE 2. To achieve the aims of the study, an online interview technique using a Mobile Instant Messaging (MIM) application, WhatsApp, was employed to gather the needed data. The mobile application was used as the main platform to collect data because the Movement Control Order (MCO) was in place when the study was conducted. Thus, the interview could not be conducted face-to-face due to the restriction. Figure 1 summarizes the procedure of the current study.

Figure 1: Study procedure

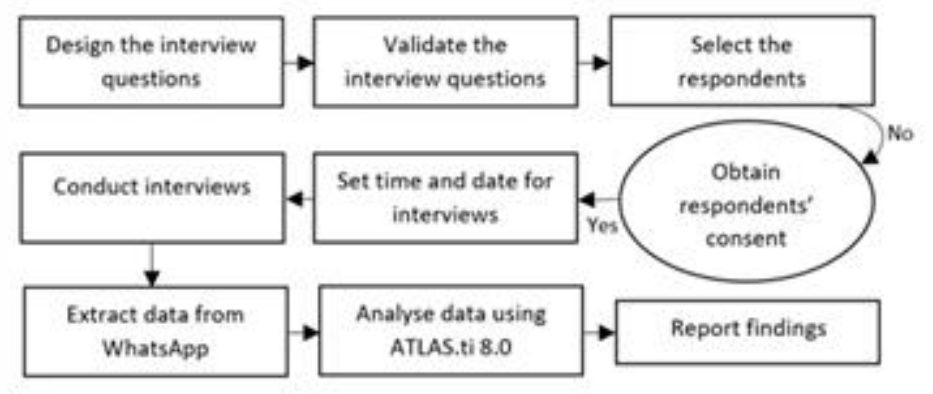

\section{Respondents}

The respondents who participated in the current study are eight secondary school teachers (T) in Terengganu. They were selected through purposive sampling. These respondents were selected from three different areas which are rural (R-Hulu Terengganu), semi urban (SU-Kemaman), urban area (UKuala Terengganu). The reason for this is to learn whether there are significant differences in terms of the respondents' perspective towards PULSE 2 in different settings. In addition, the respondents were also selected based on these criteria: (i) They have used PULSE 2 for the teaching and learning of English; (ii) They own a smartphone with Internet accessibility; and (iii) They are familiar with WhatsApp mobile application. The reason for this is to get useful responses from the respondents as the aims of the study is specifically in learning the teachers' insights with regards to PULSE 2 and the platform of the online interview is specifically via WhatsApp mobile application.

\section{Instruments}

A set of interview questions was designed adhering to the research questions developed earlier. The questions were pre-determined as a guideline for the researcher during the interview. Hence, 11 questions were constructed by the researcher in order to facilitate the semi-structured interview. Questions 6 and 7 correspond to Research Question 1 which deals with the type of textbook that the teachers prefer to use with their students. Questions 8 and 9 correspond to Research Question 2 that relates to how language skills and content have been dealt with in PULSE 2. Question 10 and 11 correspond to Research Question 3 that links to the issues that the teachers have experienced in using PULSE 2. The interview questions were checked and validated by an Associate Professor in a local university. The set of interview questions can be referred to in our Appendix.

\section{Data collection and analysis}

The qualitative data of this study was gathered through a semi-structured interview session using a mobile application, WhatsApp. The selected respondents were contacted to obtain their approval in partaking the current study. They were also informed on the objectives of the study and assured the confidentiality of their responses and anonymity. Once the respondents agreed and gave their consent, the researcher and the respondents decided the date and time of the online interview. The respondents who participated in the study are familiar with WhatsApp mobile application and do not have any problem in expressing their views through the chosen mobile application used in this study. Since the respondents' feedbacks were given in a form of text messages, no transcription was required. Each interview lasted about 20 minutes approximately. Figure 2 displays the samples of transcripts of the online interview between the respondents and the researchers via WhatsApp mobile application. 
DOI: https://doi.org/10.47405/mjssh.v6i5.777

Figure 2: Samples of WhatsApp online interview transcripts

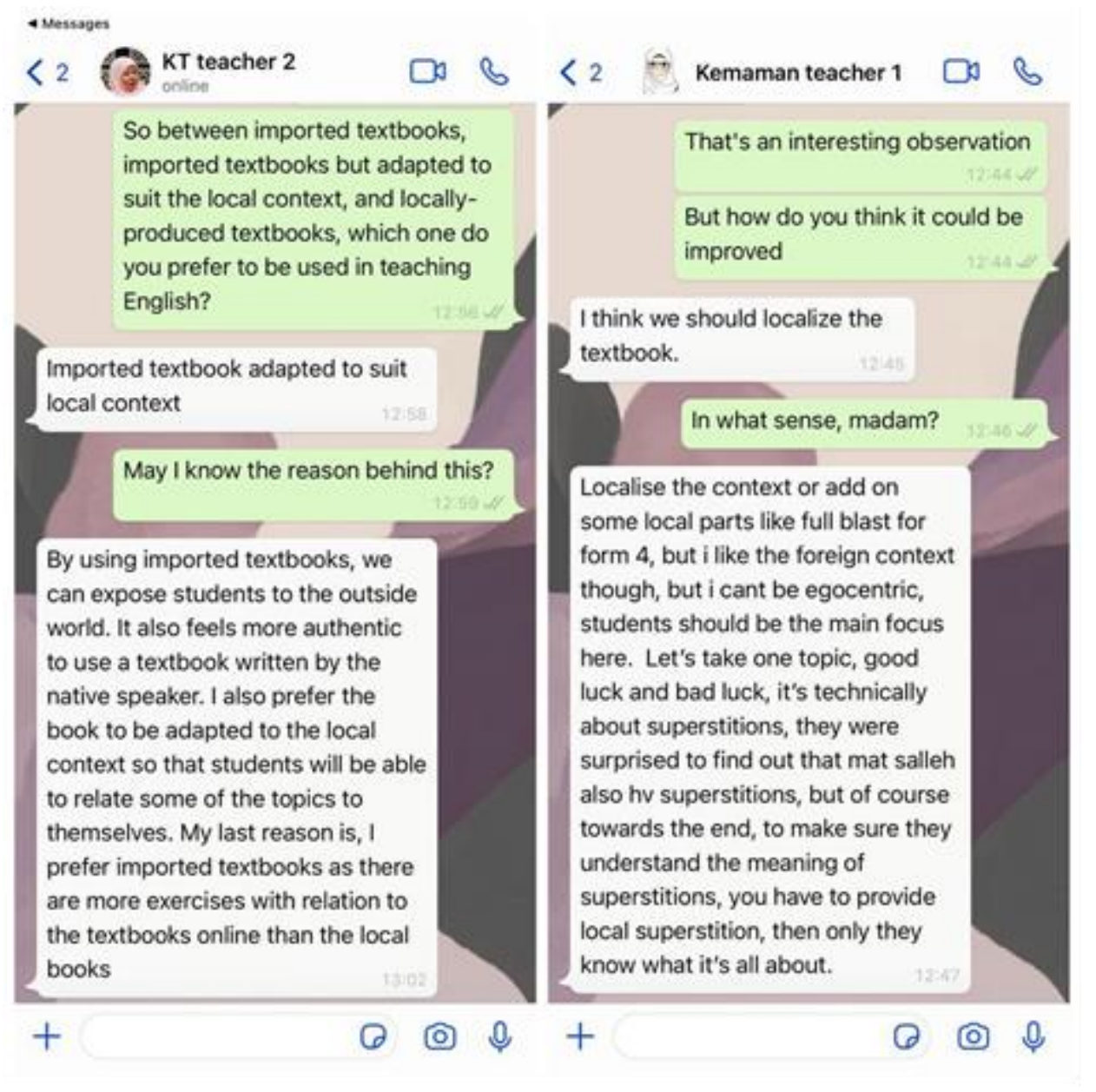

After the data has been collected, the qualitative software package ATLAS.ti was used to store and perform a systematic coding of the collected data. ATLAS.ti is one of the common computer-assisted qualitative data analysis software used by many qualitative researchers in aiding the process of data analysis. To execute this, the transcripts were initially transported into ATLAS.ti. Then the data was processed by segmenting, categorizing, and annotating it within and across different documents and categories.

\section{Result and Discussion}

\section{Research Question 1: Which type of English textbook that teachers prefer to be used with their students?}

The current study aims to explore the teachers' insights in using the PULSE 2 textbook in Malaysia. Table 1 displays the summary of the findings collected from the WhatsApp online interview based on the first Research Question.

The summary of data presented in Table 1 indicates that majority of the respondents (six - T2, T3, T5, T6, T7, \& T8) preferred imported adapted textbook compared to imported and locally produced textbooks. Three of them are from the urban area, one from semi-urban area, and the other two are from the rural area. Meanwhile, only one respondent (T4) from the rural area chose local textbook for their students. The respondent who preferred local textbook believed that locally produced textbooks are much more suitable to be used with their students' proficiency in English language. Meanwhile, the respondents who preferred imported adapted textbooks felt that these textbooks are much more authentic in terms of their content and language use compared to the locally produced textbooks. They 
also believed that the tasks given in the textbooks resemble the examination questions and include more exercises than the local ones. They added that the imported adapted textbooks provide more exposure to their students and give a sense of familiarity.

Table 1: Summary of the online interview for RQ1

\begin{tabular}{|c|c|c|}
\hline RQ & Interview Questions & Responses \\
\hline 1 & $\begin{array}{l}\text { Which type of English } \\
\text { textbook that teachers } \\
\text { prefer to be used with } \\
\text { their students? }\end{array}$ & 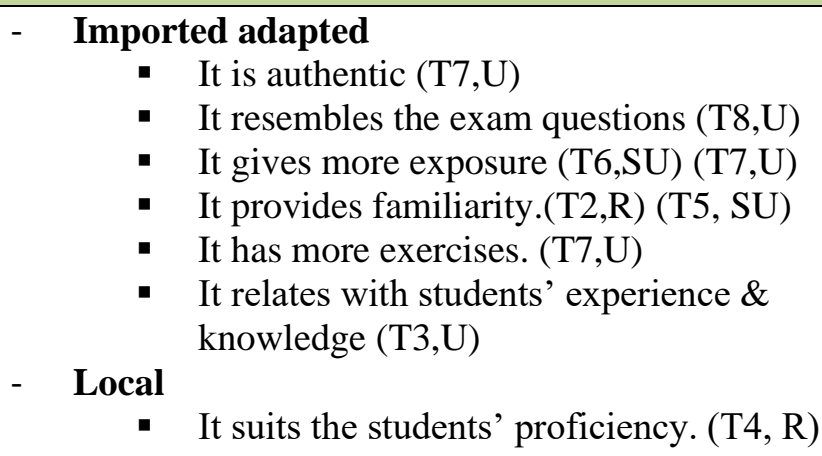 \\
\hline 1 & $\begin{array}{l}\text { Views on the } \\
\text { appearance of PULSE } 2 \\
\text { textbook. }\end{array}$ & $\begin{array}{ll} & \text { They love it. }(\mathrm{T} 8, \mathrm{U}) \\
\text { - } & \text { It looks attractive. }(\mathrm{T} 6, \mathrm{SU}) \\
\text { - } & \text { It looks modern. }(\mathrm{T} 1, \mathrm{R}) \\
\text { - } & \text { It is nice. }(\mathrm{T} 3, \mathrm{U}) \\
\text { - } & \mathrm{It} \text { is okay. }(\mathrm{T} 4, \mathrm{R})(\mathrm{T} 5, \mathrm{SU}) \\
\text { - } & \text { It has small font. }(\mathrm{T} 7, \mathrm{U}) \\
& \text { it very foreign. }(\mathrm{T} 2, \mathrm{R})\end{array}$ \\
\hline
\end{tabular}

T: Teacher; U: Urban; R: Rural; SU; Semi Urban.

In relation to the respondents' responses on PULSE 2 textbook's appearance, six respondents (T1, T3, T4, T5, T6, \& T8) gave positive view on the textbook's appearance. They stated that they love it; it looks modern and attractive, and it also looks nice. These remarks revealed that most teachers acknowledged the notable aspects of the textbook which are authentic, interesting, good, and attractive. The finding resonates with Johar and Abdul Aziz's (2019) study that found the teachers had positive opinion about their students' engagement with the textbook and acknowledged PULSE 2's appealing layout and colorful appearance. In this case, PULSE 2 has served its purpose in which according to Graves (2000, p.175), a textbook is to be used as a standard source of information that offers guidance and orientation apart from being an instrument for teaching and learning. Nevertheless, two respondents (T2 \& T7) gave negative view on the textbook's appearance. They pointed out that the textbook has small font and seems to be very foreign. This remark indicates that, since the textbook promotes cultural content that might be distant and alien for many Malaysian students, it is considered that the textbook has lack of relevance to the local context. Students learn best when they are able to connect the content with their real life. Hence, it invites potential threat to language learning, as it hinders students' understanding of certain topics and affects their performance in language learning. This could potentially widen the learning gap between students in urban schools and those in the rural ones ('Let's have our own textbooks', 2018). In addition, with minimal direct connection to the students' schemata, learning could not take place efficiently as "the students' schemata and previous knowledge should be connected well" (Johar \& Abdul Aziz, 2019, p.13). Thus, using a local content would benefit the second language learners more.

Nonetheless, there are other perceptions that oppose to this belief. Some said that foreign content can create more learning opportunities which helps to improve students' knowledge and at the same time preparing them for life in the 21st century (Aziz, 2017). Chaining to the idea of globalized world, it is important for students to be exposed to various contents that promote a larger global exposure, specifically towards understanding different culture practices. This is supported by Johar and Abdul Aziz (2019) as their study found that even though the teachers believed the content of PULSE 2 is quite challenging for low level students, it is still engaging and useful to be used in their lessons due to its 
variety of activities. To deduce, due to the mixed reactions on the practicality of the textbook, further studies should be conducted in revealing other hidden issues pertaining to the use of PULSE 2.

\section{Research Question 2: How have language skills and content been dealt with in PULSE 2 according to teachers?}

Table 2: Summary of the online interview for RQ2

\begin{tabular}{|c|c|c|}
\hline RQ & $\begin{array}{l}\text { Interview } \\
\text { Questions }\end{array}$ & Responses \\
\hline 2 & $\begin{array}{l}\text { How have } \\
\text { language skills } \\
\text { and content been } \\
\text { dealt with in } \\
\text { PULSE } 2 \\
\text { according to } \\
\text { teachers? }\end{array}$ & $\begin{array}{l}\text { - } \quad \text { They are equally dealt with. }(\mathrm{T} 5, \mathrm{SU})(\mathrm{T} 8, \mathrm{U}) \\
\text { - } \\
\text { - } \\
\text { - } \\
\text { - }\end{array}$ \\
\hline
\end{tabular}

\section{T: Teacher; U: Urban; R: Rural; SU; Semi Urban}

The data presented in Table 2 relates to the respondents' perception of how language skills and content are dealt within PULSE 2 textbook. Four respondents have positive feedbacks towards both content and language skills in PULSE 2 and majority of the feedbacks are from the teachers who teach in the urban area, and two from the semi urban area. Most of the respondents from both the urban as well as semi-urban area think that the content and language are well-dealt with (T1 \& T7), good (T3), equally dealt with (T5 \& T8), and incorporated with one another (T6). Only one respondent from the rural area stated that they are well-dealt with.

Meanwhile, two respondents from the rural area have negative feedbacks towards the question which they believed that both elements in PULSE 2 are not interesting enough (T2), not parallel with one another (T2), and unsuitable to be used in rural schools (T4). Since the two negative remarks were raised by teachers from the rural area, they may be linked to the foreign content of the textbook. This should be taken seriously as using materials that are vastly different from the local context could be simply too much, as it will make the learners especially from the rural areas to feel like they are in an alien environment (Chow, 2017), hence affecting their ability to enhance their proficiency in the referred language. This is due to the fact that foreign content provides additional mental burden to the L2 learners as they must digest the global content and acquire the language at the same time (Ariz, 2017b; Hammim, 2018).

Apart from that, it is also discovered that only one respondent from the semi-urban area who believed some parts in the textbook can be too easy and some parts are too difficult (T5). The finding is parallel with Johar and Abdul Aziz's (2019) study as their respondents believed that the textbook is too difficult for the students specifically the vocabularies and they also believed this might hamper the students to achieve the 'A2' CEFR level as indicated by the MOE. To sum up, teachers from the rural area seemed to be worried with the use of the textbook for their students

\section{Research Question 3: What are the issues that the teachers have experienced in using PULSE 2?}

The data presented in Table 3 reveals that the issues that the teachers have experienced while using PULSE 2 are related to its language content as well as teaching and learning problems. In relation to language content, PULSE 2 has received quite a number of negative reviews from the respondents and most of them are from the urban area which has the total number of 4 respondents. An equal number of two are from the semi-urban and rural area. The language content is said to be unorganized (T2), is too 
difficult and hard for students to understand (T8), contains too many repetitions (T7), has poor audio quality (T5), and is deemed as unsuitable especially for rural school students (T4). Only three positive reviews were retrieved related to the language content from each area respectively. All of the respondents agreed that the language content is well structured (T1), good (T3), and contains vocabulary and pronunciation content that is provided at the beginning of a particular unit (T6). Only one respondent from the semi-urban area has aa balanced feedback towards the language content in PULSE 2 in which some parts are noted to be too easy and some parts are way thought to be too difficult for students to cope (T5).

Table 3: Summary of the online interview for RQ3

\begin{tabular}{|c|c|c|}
\hline RQ & Interview Questions & Responses \\
\hline 3 & $\begin{array}{l}\text { What are the issues that the } \\
\text { teachers have experienced in using } \\
\text { PULSE 2? }\end{array}$ & $\begin{array}{l}\text { Language content } \\
\text { - } \text { It is not well organized. }(\mathrm{T} 2, \mathrm{R}) \\
\text { - } \text { It is okay. }(\mathrm{T} 3, \mathrm{U}) \\
\text { - } \text { It has poor audio quality. }(\mathrm{T} 5, \mathrm{SU}) \\
\text { - } \text { It has repetition. }(\mathrm{T} 7, \mathrm{U}) \\
\text { - } \text { It is too difficult. }(\mathrm{T} 8, \mathrm{U}) \\
\text { - } \text { It is too hard. }(\mathrm{T} 8, \mathrm{U}) \\
\text { - } \text { It is unsuitable. . }(\mathrm{T} 4, \mathrm{R}) \\
\text { - } \text { The vocab and pronunciation dealt at } \\
\text { - } \text { the beginning. }(\mathrm{T} 6, \mathrm{SU}) \\
\text { - } \text { It is well.(T1,R) } \\
\text { Pome parts can be too easy and some } \\
\text { parts are too difficult }(\mathrm{T} 5, \mathrm{SU})\end{array}$ \\
\hline
\end{tabular}

3 How do you think PULSE 2 can be improved?

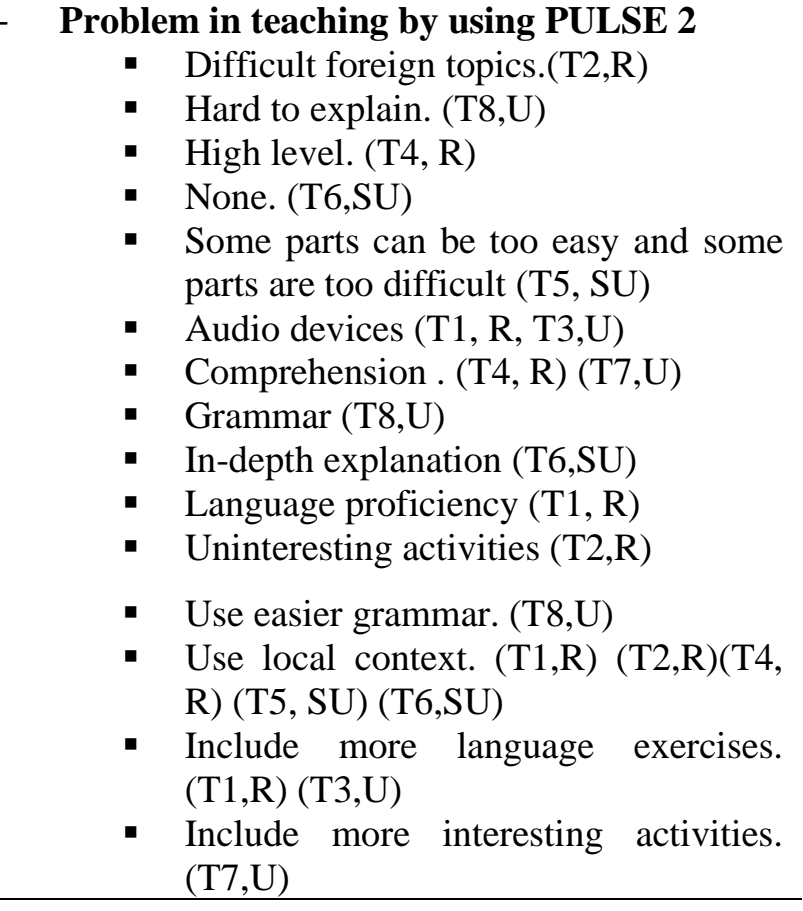

- Hard to explain. $(\mathrm{T} 8, \mathrm{U})$

- None. (T6,SU)

- Some parts can be too easy and some

Audio devices (T1, R, T3,U)

- Comprehension . (T4, R) $(\mathrm{T} 7, \mathrm{U})$

- Grammar (T8,U)

- In-depth explanation (T6,SU)

- Language proficiency $(\mathrm{T} 1, \mathrm{R})$

- Use easier grammar. $(\mathrm{T} 8, \mathrm{U})$

Use local context. $(\mathrm{T} 1, \mathrm{R})(\mathrm{T} 2, \mathrm{R})(\mathrm{T} 4$, R) $(\mathrm{T} 5, \mathrm{SU})(\mathrm{T} 6, \mathrm{SU})$ $(\mathrm{T} 1, \mathrm{R})(\mathrm{T} 3, \mathrm{U})$ $(\mathrm{T} 7, \mathrm{U})$

\section{T: Teacher; U: Urban; R: Rural; SU; Semi Urban.}

Apart from that, the respondents also highlighted several issues that they faced while using PULSE 2 in their classroom. Most of the issues were voiced by the respondents from the rural area, such as the difficulties of their students to understand difficult foreign topics (T2), the high level of English used in PULSE 2 (T4), and the uninteresting activities offered by the book due to its foreign content, which has hindered the students from relating to the content well (T2). Some of there rural teachers' concerns 
were also shared by the teachers in the urban area, especially in terms of getting access to PULSE 2's multimedia content (T1, T3) and its comprehension issues among the students (T4, T7). In addition, a teacher from the urban area was also raising alarms about its grammar level (T8), which was deemed as unsuitable for second language learners unless they aspire to become an English teacher later. On the other hand, the teachers from the semi urban area indicated the imbalanced of difficulties in PULSE 2, where some parts are deemed as too easy while some others are too difficult (T5). This required additional time for the teachers to provide in-depth explanations about the content and the activities in PULSE 2 (T6). Interestingly, one teacher from the semi urban area admitted that she encountered no issue while using PULSE 2 in her classroom.

Unsurprisingly, when asked about how PULSE 2 can be improved, majority of the teachers across the rural and semi urban areas believed that its content could be improved with the inclusion of additional local contexts that could their students' understanding (T1, T2, T4, T5, T6). While the teachers from the urban area were more focused on the language contents in the book, as they wished for the use of easier grammar in the book (T8), more language exercises (T3) and more interesting activities to cater to their more advanced students (T7). This is in a way has indicated the different focuses of teachers from different areas, where the teachers from the rural and semi urban areas seem to be more focused on the book's content in general while their counterparts in the urban area seem to be more fixated on the language content of PULSE 2.

\section{Conclusion}

To conclude, the study has discovered that imported English textbooks with local modifications are preferred by the respondents, as opposed to the locally produced English textbooks. The respondents on the other hand seem to be conflicted on how the language content and skills are being covered by PULSE 2, while highlighting its vast level of difficulties, suitability, and appeal to their students. Not only that, the respondents also have also raised concerns about its mismatched language level, inaccessible multimedia components, and most importantly, its difficult foreign content. It can be said that these teachers still have their reservations in using PULSE 2, even after three years of its introduction.

In short, these findings exemplify how foreign textbooks can be perceived as irrelevant, culturally unfitting, incompatible with the latest teaching methodology, of mixed levels and incapable of meeting the wide range of needs of their users when it comes to language skill teaching (Khoo \& Knight, 2015), thus the use of foreign textbook should be revised to suit the students' language proficiency. Even though textbooks with foreign content are frequently acknowledged to offer many benefits in teaching second language learners, the practicality of it has continuously been questioned in reality and caused debates among language educators (Khoo \& Knight, 2015). Perhaps, the best way of addressing this situation is by having textbooks that offer a balanced cultural content, as recommended by Deswila et al. (2021).

It could be said that one of the motivations behind the roll-out of PULSE 2 is to promote students' acceptance of other cultures and broadening their viewpoint in aspects like culture, religion, and lifestyle (Ariz, 2017a: Deswila et al., 2021). However, more studies are required to investigate how this ideal concept can be materialized especially for the students in the rural area. The concerns on foreign content from a teacher in the rural area in the current study should be taken seriously. It is recommended that future studies should be executed in examining not just teachers, but also students' insights in the use of PULSE 2. Studies which involve a bigger population can also help to see the issues in a bigger picture. Likewise, such studies are pertinent to ensure that no student will be left behind in the efforts to help them to become proficient in English according to the global standards.

While it is vital to remember that a textbook is just a tool in teaching and learning, and "it does not make the teacher [and] it is nothing without a good teacher" (Aziz, 2017, p.1), relevant stakeholders such as the MOE ought to have another hard look at the use of imported English textbooks in Malaysian schools, whether to continue the use of these books, or suggest an alternative version of 
these textbooks with local modifications, or abandon them altogether in favor of locally produced English textbooks that are aligned with the elements of the CEFR. Ultimately, this matter will bear an impact on the successful creation of Malaysia's own version of the CEFR called 'CEFR-M' by the end of the ongoing English Language Education Reform in Malaysia in 2025 (MOE, 2015).

Looking at the current scenario of today's learning with the sudden shift to the 'new normal' in education thanks to the COVID-10 pandemic which shows no sign of slowing down, the selection of learning materials such as textbooks should be given a renewed and greater emphasis. Undoubtedly, not all students are privileged to have access to the teaching and learning process that is happening mainly online and remotely nowadays. For some, a textbook is their only way to have a continuous access to education as it can be used easily for self-study and is readily available without having the needs to own advanced technological devices. A textbook could offer them a glimpse of hope and access to the world during this pandemic. They already have tough times adjusting to and understanding the pandemic and the new normal; Let us not shatter that hope and add to that burden by offering a textbook that is ultimately foreign, decidedly arduous, and hugely unrelatable to them.

\section{References}

Abdul Aziz. A.H.A. Ab Rashid, R., \& Wan Zainudin, W.Z. (2018). The enactment of the Malaysian Common European framework of reference (CEFR): National master trainer's reflection. Indonesian Journal of Applied Linguistics, 8(2), 409-417.

Al-Shammari, A. K. (2015). Developing the English Curriculum in the Kingdom of Saudi Arabia: Possibilities and challenges. Arab World English Journal, 6(4), 365-372.

Ariz, N.A. (2017a, October 7). Free Malaysia Today. Imported English textbooks will boost students' proficiency. Retrieved from https://www.freemalaysiatoday.com/category/ nation/2017/10/07/imported-english-textbooks-will-boost-students-proficiency/.

Ariz, N.A. (2017b, December 2). Free Malaysia Today. Imported textbooks: Issue is relevance of content, not Spanish words. Retrieved from https://www.freemalaysiatoday.com/ category/nation/2017/12/02/imported-textbooks-issue-is-relevance-of-content-not-spanishwords/.

Ariz, N.A. (2017c, December 12). Free Malaysia Today. New books: English Teachers must know what to teach. Retrieved from https://www.freemalaysiatoday.com/category/ nation/2017/12/12/new-books-english-teachers-must-know-what-to-teach-says-page/.

Aytug, S. (2007). An EFL textbook evaluation study in Anatolian high schools: 'New Bridge to Success for 9th Grade New Beginners' (Unpublished Master Dissertation). Bilkent University, Turkey.

Aziz, H. (2017, December 6). New Straits Times. Textbook do not make the teachers. Retrieved from https://www.nst.com.my/opinion/columnists/2017/12/311230/ textbooks-do-not-make-teacher

Bader, F. (2017). An evaluation of the Algerian Middle School English syllabuses and textbooks (Unpublished Doctoral Dissertation). University "Des Frères Mentouri", Algeria.

Chin, C. \& Rajaendram, R. (2017, October 5). The Star. Only imported English textbooks from next year. Retrieved from https://www.thestar.com.my/news/nation/2017/10/05/ only-importedenglish-textbooks-from-next-year-move-part-of-reform-to-ensure- international- proficient.

Chow, M.D. (2017, October 11). Free Malaysia Today. Academic calls for localized English texts. Retrieved from https://www.freemalaysiatoday.com/category/nation/2017/ 10/11/academiccalls-for-localised-english-texts/.

Cunningsworth, A. (1984). Evaluating and selecting EFL teaching materials. Heinemann Education.

Deswila, N., Kustati, M., Yusuf, Y. Q., Raja Harun, R. N. S., Besral, \& Rehani. (2021). Cultural contents in the ELT textbook prepared by the Indonesian ministry of education for secondary schools. Journal of Nusantara Studies, 6(1), 222-241. http://dx.doi.org/10.24200/jonus.vol6iss1pp222-241

Goh, Y.T. \& Abdul Aziz, A. (2020). Using PULSE 2 to teach and assess Malaysian pupils' speaking skill. International Journal of Publications and Social Studies, 5(1), 55-68.

Graves, K. (2000). Designing language course: A guide for teachers. Boston. Heinle. Cengage Learning. 
Hammim, R. (2018, January 8). New Straits Times. JELTA wants Education Ministry to rethink used of imported textbooks. Retrieved from https://www.nst.com.my /news/nation/2018/01/322975/jelta-wants-education-ministry-rethink-use-imported-textbooks.

Johar, N. A. I. N., \& Aziz, A. A. (2019). Teachers perceptions on using the Pulse 2 textbook. Journal of Educational Research \& Indigenous Studies, 2(1), 1-15.

Johari, Z.K. (2017a, December 11). The Malaysian Times. Teachers, students, will be hampered by the introduction of new "imported" textbooks. Retrieved from http://www.themalaysiantimes.com.my/teachers-students-will-hampered-introduction-newimported-textbooks/.

Johari, Z.K. (2017b, December 3). MOE's reply raises more questions than Answers about "imported" English textbooks. [Press Release]. Retrieved from https://dapmalaysia .org/statements/2017/12/03/26208/

Khoo, H. S., \& Knight, P. (2015) Teachers' Evaluation of KBSM Form 4, 5 English Textbooks Used in the Secondary Schools in Penang, Malaysia. Advances in Language and Literary Studies, 6(4), 128-150.

Krashen, S.D. (1982). Principles and practice in second language acquisition. Pergamon Press.

Let's have our own textbooks. (2018, February 4). The Star. Retrieved from https://www.thestar.com.my/news/education/2018/02/04/lets-have-our-own- textbooks/.

Marlina, R. (2017). Teaching English as an international language: Implementing, Reviewing, and reenvisioning world Englishes in language education. Routledge.

Misbah, N. H., Mohamad, M., Yunus, M. M., \& Yaacob, A. (2017). Identifying the factors contributing to students' difficulties in the English language learning. Creative Education, 8(13), 1999-2008. Available at: http://doi.org/10.4236/ce.2017.813136

MoE (Ministry of Education Malaysia). (2015). English Language education reform in Malaysia: The Roadmap 2015-2025. Ministry of Education Malaysia.

Mukundan, J. \& Rezvani Kalajahi, S.A. (2013). Evaluation of Malaysian English language teaching textbooks. International Journal of Education \& Literacy Studies, 1(1), 38-46.

Nguyen, C.T. (2015). An Evaluation of the textbook English 6: A case study from secondary schools in the Mekong Delta Provinces of Vietnam (Unpublished Doctoral Dissertation). University of Sheffield, England.

Pulverness, A., \& Tomlinson, B. (2013). Materials for cultural awareness. In B. Tomlinson (Ed.), Developing materials for language teaching (pp. 443-460). Bloomsbury Academic.

Richards, J. (1998). Textbooks: Help or hindrance in teaching?. Cambridge University Press.

Teachers not trained properly to use English textbooks, says parents' group. (2017, December 3). Free Malaysia Today. Retrieved from https://www.freemalaysiatoday.com/ category/nation/2017/12/03/teachers-not-trained-properly-to-use-imported-english-textbookssays-parents-group/.

Thirunavukarasu, I., \& Raja Harun, R. N. S. (2021). The effects of cultural based text types in reading comprehension. Journal of Nusantara Studies, 6(1), 123.http://dx.doi.org/10.24200/jonus.vol6iss1pp1-23

'Why weren't imported textbooks purchased through open tender?'. (2017, November 25). Free Malaysia Today. Retrieved from https://www.freemalaysiatoday.com/category/ nation/2017/11/25/why-werent-imported-textbooks-purchased-through-open-tender. 